NASA/TM—2008-215210

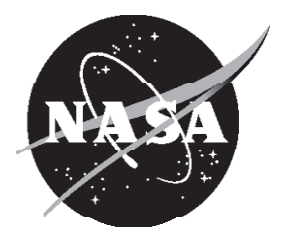

\title{
Moisture-Induced Delamination Video of an Oxidized Thermal Barrier Coating
}

James L. Smialek, Dongming Zhu, and Michael D. Cuy Glenn Research Center, Cleveland, Ohio 


\section{NASA STI Program . . . in Profile}

Since its founding, NASA has been dedicated to the advancement of aeronautics and space science. The NASA Scientific and Technical Information (STI) program plays a key part in helping NASA maintain this important role.

The NASA STI Program operates under the auspices of the Agency Chief Information Officer. It collects, organizes, provides for archiving, and disseminates NASA's STI. The NASA STI program provides access to the NASA Aeronautics and Space Database and its public interface, the NASA Technical Reports Server, thus providing one of the largest collections of aeronautical and space science STI in the world. Results are published in both non-NASA channels and by NASA in the NASA STI Report Series, which includes the following report types:

- TECHNICAL PUBLICATION. Reports of completed research or a major significant phase of research that present the results of NASA programs and include extensive data or theoretical analysis. Includes compilations of significant scientific and technical data and information deemed to be of continuing reference value. NASA counterpart of peer-reviewed formal professional papers but has less stringent limitations on manuscript length and extent of graphic presentations.

- TECHNICAL MEMORANDUM. Scientific and technical findings that are preliminary or of specialized interest, e.g., quick release reports, working papers, and bibliographies that contain minimal annotation. Does not contain extensive analysis.

- CONTRACTOR REPORT. Scientific and technical findings by NASA-sponsored contractors and grantees.

- CONFERENCE PUBLICATION. Collected papers from scientific and technical conferences, symposia, seminars, or other meetings sponsored or cosponsored by NASA.

- SPECIAL PUBLICATION. Scientific, technical, or historical information from NASA programs, projects, and missions, often concerned with subjects having substantial public interest.

- TECHNICAL TRANSLATION. Englishlanguage translations of foreign scientific and technical material pertinent to NASA's mission.

Specialized services also include creating custom thesauri, building customized databases, organizing and publishing research results.

For more information about the NASA STI program, see the following:

- Access the NASA STI program home page at http://www.sti.nasa.gov

- E-mail your question via the Internet to help@ sti.nasa.gov

- Fax your question to the NASA STI Help Desk at 301-621-0134

- Telephone the NASA STI Help Desk at 301-621-0390

- Write to: NASA Center for AeroSpace Information (CASI) 7115 Standard Drive Hanover, MD 21076-1320 
NASA/TM-2008-215210

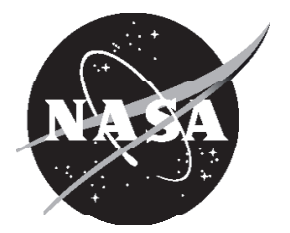

\section{Moisture-Induced Delamination Video of an Oxidized Thermal Barrier Coating}

James L. Smialek, Dongming Zhu, and Michael D. Cuy Glenn Research Center, Cleveland, Ohio

National Aeronautics and

Space Administration

Glenn Research Center

Cleveland, Ohio 44135 
This work was sponsored by the Fundamental Aeronautics Program at the NASA Glenn Research Center.

Level of Review: This material has been technically reviewed by technical management.

Available from

NASA Center for Aerospace Information

7115 Standard Drive

Hanover, MD 21076-1320
National Technical Information Service 5285 Port Royal Road Springfield, VA 22161

Available electronically at http://gltrs.grc.nasa.gov 


\title{
Moisture-Induced Delamination Video of an Oxidized Thermal Barrier Coating
}

\author{
James L. Smialek, Dongming Zhu, and Michael D. Cuy \\ National Aeronautics and Space Administration \\ Glenn Research Center \\ Cleveland, Ohio 44135
}

\begin{abstract}
PVD TBC coatings were thermally cycled to near-failure at $1150{ }^{\circ} \mathrm{C}$. Normal failure occurred after 200 to 3001 -hr cycles with only moderate weight gains $\left(0.5 \mathrm{mg} / \mathrm{cm}^{2}\right)$. Delamination and buckling was often delayed until well after cooldown (desktop spallation), but could be instantly induced by the application of water drops, as shown in an accompanying video-recording. Moisture therefore plays a primary role in delayed desktop TBC failure. Hydrogen embrittlement is proposed as the underlying mechanism.
\end{abstract}

\section{Introduction}

Thermal barrier coatings (TBC) are known to fail from a number of contributing factors: thermal expansion mismatch stresses upon cycling, stress concentrations due to thermally grown scales and asperities in the bond coat, increased strain energy in the scale, interfacial impurities and failure between the scale and the bond coat, creep-ratcheting of the bond coat, and sintering of the yttria stabilized zirconia (YSZ) top coat (leading to increased modulus, stress, and strain energy) (refs. 1 and 2).

For the purposes of this paper, it is helpful to recall that the protective thermally grown alumina scales adhere to $\mathrm{NiAl}$ and $\mathrm{NiCrAl}$ bond coats as long as detrimental sulfur impurity segregation effects are negated by low sulfur $(<0.5 \mathrm{ppmw})$ alloys, reactive element gettering, or Pt alloying. Nevertheless, in laboratory thermal cycling furnace oxidation tests, TBCs and alumina scales are seen to fail with some component of alumina-alloy interfacial failure. Furthermore, this interfacial failure is exacerbated by the presence of moisture in the ambient environment, whether intentional or not. In many cases the phenomenon of moisture-induced delayed spallation (MIDS) is observed, where the scale does not fail immediately after cooldown but requires some additional incubation time for failure to occur. Indeed the application of liquid water has been used to initiate failure (refs. 3 and 4).

Similarly, TBCs may not fail immediately upon cooldown, but remain intact for some period of hours, until failing catastrophically by some unseen factor (refs. 5 to 8). In our early work, we have termed this phenomenon as desktop spallation (DTS) to describe the delayed failure of no-bond coat TBCs and "alligatoring" as the gradual propagation of a gaping edge crack that progressively detaches the coating (ref. 7). Furthermore, water immersion was found to detach initially adherent coatings. It is therefore believed that the MIDS and DTS phenomena are related. The purpose of the present letter is to present a video sequence of images and characterize the failure of an oxidized EB-PVD TBC upon the application of water drops. A companion paper confirms this effect with video of moisture-induced failure of plasma sprayed YSZ coatings on PVD NiCoCrAlY bond coats (ref. 9). Moisture-induced delayed TBC failures are then discussed in terms of an interfacial chemical mechanism. 


\section{Experimental}

Thermal barrier coatings samples were obtained from GE Aviation produced by a commercial vendor (Howmet). The substrate was Rene'N5 with the conventional Pt-modified aluminide bond coat. The test samples were $3.3 \mathrm{~mm}$ thick by $2.54 \mathrm{~cm}$ diameter discs. and the EB-PVD TBC was deposited on one side only to a thickness of approximately $210 \mu \mathrm{m}$. The obverse exposed aluminide side contained nubs remaining from spot welds to a mounting sheet for the coating reactor. These were carefully polished off without removing the aluminide coating. Also, a thin overcoat of TBC material was carefully polished off the circumferential edge of the samples to avoid any perturbations in the weight change curve due to edge spalling. The exposed edge subsequently allowed direct access of moisture to the exposed bond coat-TBC interface. The specific top coat discussed here contained about half the conventional $\mathrm{Y}_{2} \mathrm{O}_{3}$ content, (i.e., $2 \mathrm{~mol} \% \mathrm{YO}_{1.5}$ ) made up by $\mathrm{Gd}$ and $\mathrm{Yb}$ oxide co-dopants (1.5 $\mathrm{mol} \% \mathrm{MO}_{1.5}$, each) (ref. 10). A larger sample set included the standard 8YSZ (4 mol\% $\left.\mathrm{YO}_{1.5}\right)$ composition as well as more variants of $\mathrm{Y}, \mathrm{Gd}, \mathrm{Yb}, \mathrm{Ti}$, and $\mathrm{Ta}$ oxide dopants.

Oxidation was performed in a vertical tube, cyclic oxidation furnace apparatus. The hot zone was maintained at $1150{ }^{\circ} \mathrm{C}$, with about $\pm 2{ }^{\circ} \mathrm{C}$ variability, somewhat dependent on the specific tube. The samples were held in Pt baskets and cooled by retraction to the upper level $\sim 150{ }^{\circ} \mathrm{C}$, but not out of the tube, to avoid any misalignment issues upon lowering for reheating. Samples were weighed at $0,1,2,5,10,20,30$, and $40 \mathrm{hr}$ and every $20 \mathrm{hr}$ thereafter, corrected against a $10.00000 \mathrm{gm}$ standard weight, producing about $0.02 \mathrm{mg}$ accuracy for samples having nominally $13 \mathrm{~cm}^{2}$ surface area. The samples were advanced into adjacent tubes after each inspection in order to eliminate any possible systematic error introduced by a given tube. Coating surfaces were visually examined in oblique lighting for any precursors of failure, as well as for small cracks under a microscope at 100x. Some samples were exposed to moist breath and water drops immediately upon removal from the furnace, as failure became more probable near 200 to $300 \mathrm{hr}$. of testing. A digital camera was used to obtain $30 \mathrm{sec}$ video clips of the resultant behavior. Again, oblique lighting (at $\sim 5^{\circ}$ angle) from a fiber optic light source was used to accentuate surface relief arising from any delamination and lifting.

\section{Results}

The weight change of a bare aluminized sample (with no TBC) is shown as the solid line in figure 1, reaching about $1 \mathrm{mg} / \mathrm{cm}^{2}$ after $300 \mathrm{hr}$. By comparison, the subject TBC sample (diamonds) gained less weight, about $0.5 \mathrm{mg} / \mathrm{cm}^{2}$. This suggests that the TBC covering one side of the sample reduced the overall weight gain substantially. Using the conventional conversion resulting from the $3.99 \mathrm{gm} / \mathrm{cm}^{3}$ density of $\alpha-\mathrm{Al}_{2} \mathrm{O}_{3}$, this translates to an $\alpha-\mathrm{Al}_{2} \mathrm{O}_{3}$ scale of about 5.3 and $2.7 \mu \mathrm{m}$ for these two samples, respectively. The TBC weight gain data is seen to behave quite regularly, generally showing no perturbations that might result from random TBC microspallation, except at $100 \mathrm{hr}$. Finally, data from an uncoated Rene' N5 + 50 ppmw Y sample is seen to lie between both curves (ref. 11). 


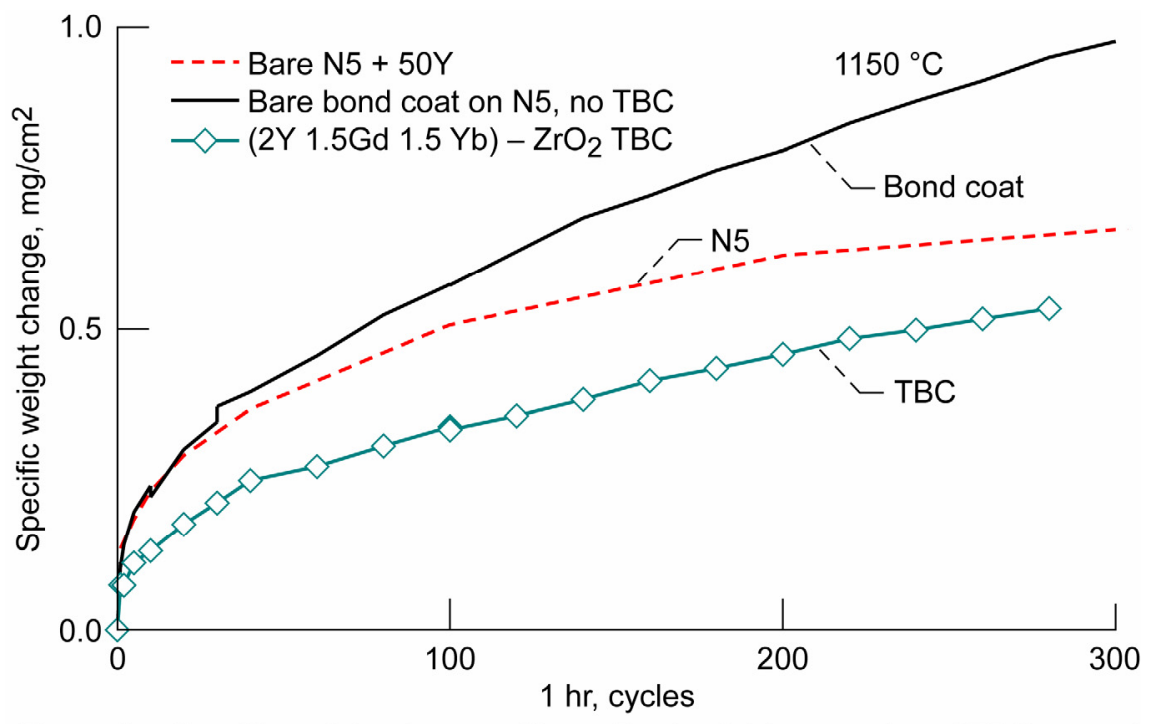

Figure 1.-Specific weight change of bare, Pt-aluminide-coated, and TBC-coated Rene'N5 disc samples, oxidized at $1150^{\circ} \mathrm{C}$ using 1-hr cycles.

The TBC was seen to be intact after $100 \mathrm{hr}$, with essentially no distinguishing features, despite additional handling for photography. Similarly, figure 2 shows an intact TBC of the same sample $(210 \mu \mathrm{m} \text { of EB-PVD (Y-Gd-Yb })_{2} \mathrm{O}_{3}$ stabilized $\mathrm{ZrO}_{2}, \mathrm{Ni}(\mathrm{Pt}) \mathrm{Al}$ bond coat on Rene'N5), after cooldown from 300 1-hr furnace oxidation cycles at $1150{ }^{\circ} \mathrm{C}$. A video clip (30 sec) showing real-time failure of this sample due to moisture can be viewed by clicking on figure 2 in the online version of this report which can be found at http://gltrs.grc.nasa.gov. Two water drops were applied from a water bottle, showing a large meniscus for the first $3 \mathrm{sec}$. After about $6 \mathrm{sec}$, a north-south edge crack begins at the 12 o'clock position, then propagates and branches out over the entire surface. The coating is completely delaminated within $3 \mathrm{sec}$ after the appearance of this first crack. Figure 3 presents images captured from the video in figure 2, allowing examination of crack structure at times labeled on each macrograph, in seconds.

The time from the first application of water until a specific crack was formed is labeled on the final still photo of figure 4 . Here about 6 sec elapsed before the first crack appeared, and approximately 3 more sec were required to fail the entire surface. These time intervals refer primarily to the incubation of a crack rather than propagation. The actual crack velocity was much faster, as viewed in real time.

Preliminary observation via optical microscopy revealed very little retained TBC material, islands of alumina scale embedded into the bond coat, and a continuous sea of bare metal. The latter featured the tell-tale interfacial imprints of the previously adjacent alumina grains and a fair degree of surface undulation. Some of these features can be discerned in the low magnification macrograph of figure 5.

From the data above, one can conclude that failure of the TBC was commensurate with, and probably caused by, failure of the alumina scale at the scale-metal interface. Little evidence existed, either from surface morphology or weight change, to indicate any precursor to this massive catastrophic TBC delamination failure. The primary source of suspicion was the failure 


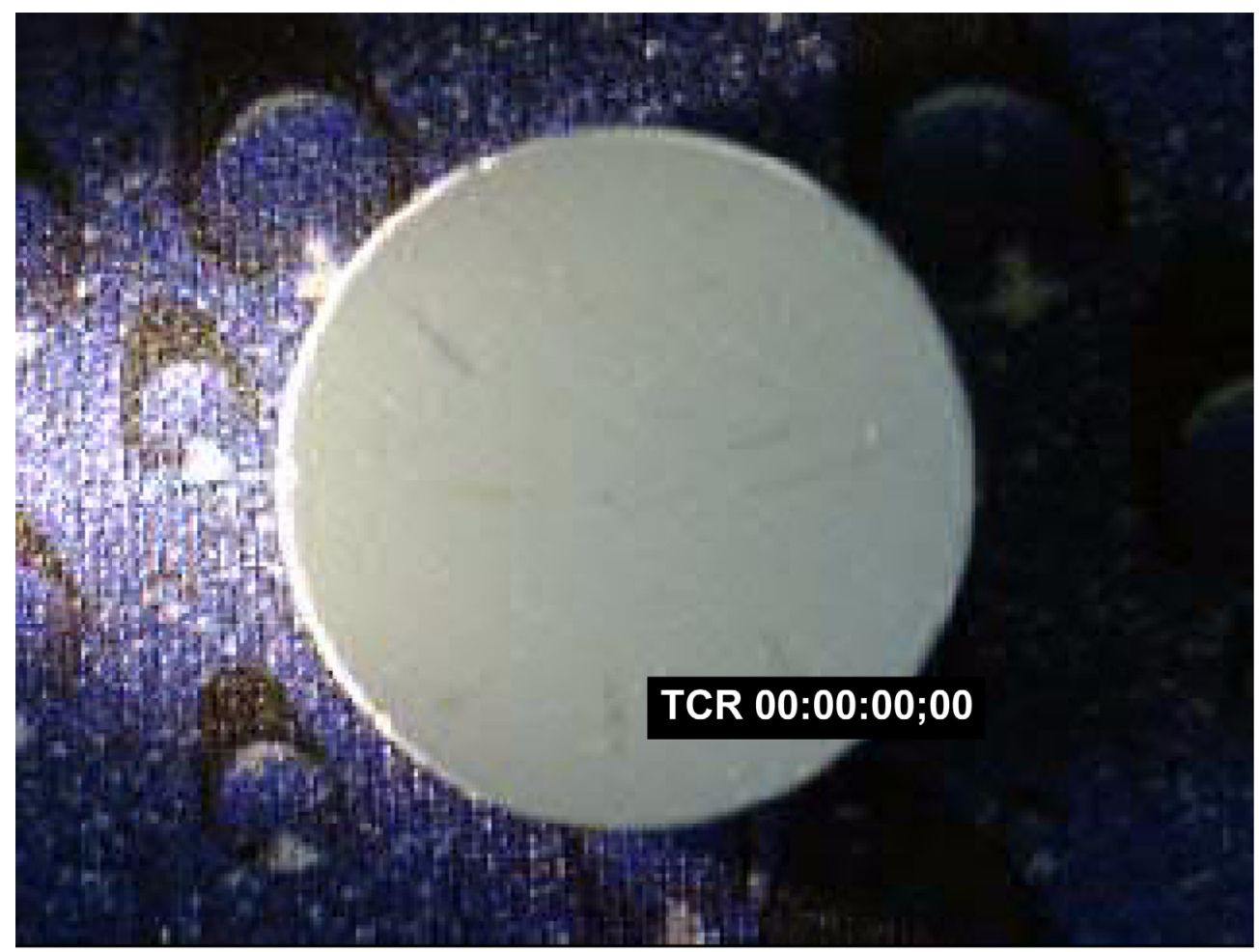

Figure 2.-Video file of water-induced TBC failure. Moisture-induced delayed failure, EB-PVD RE-YSZ, Ni(Pt)Al, Rene'N5, $1150^{\circ} \mathrm{C}, 300$ cycles.
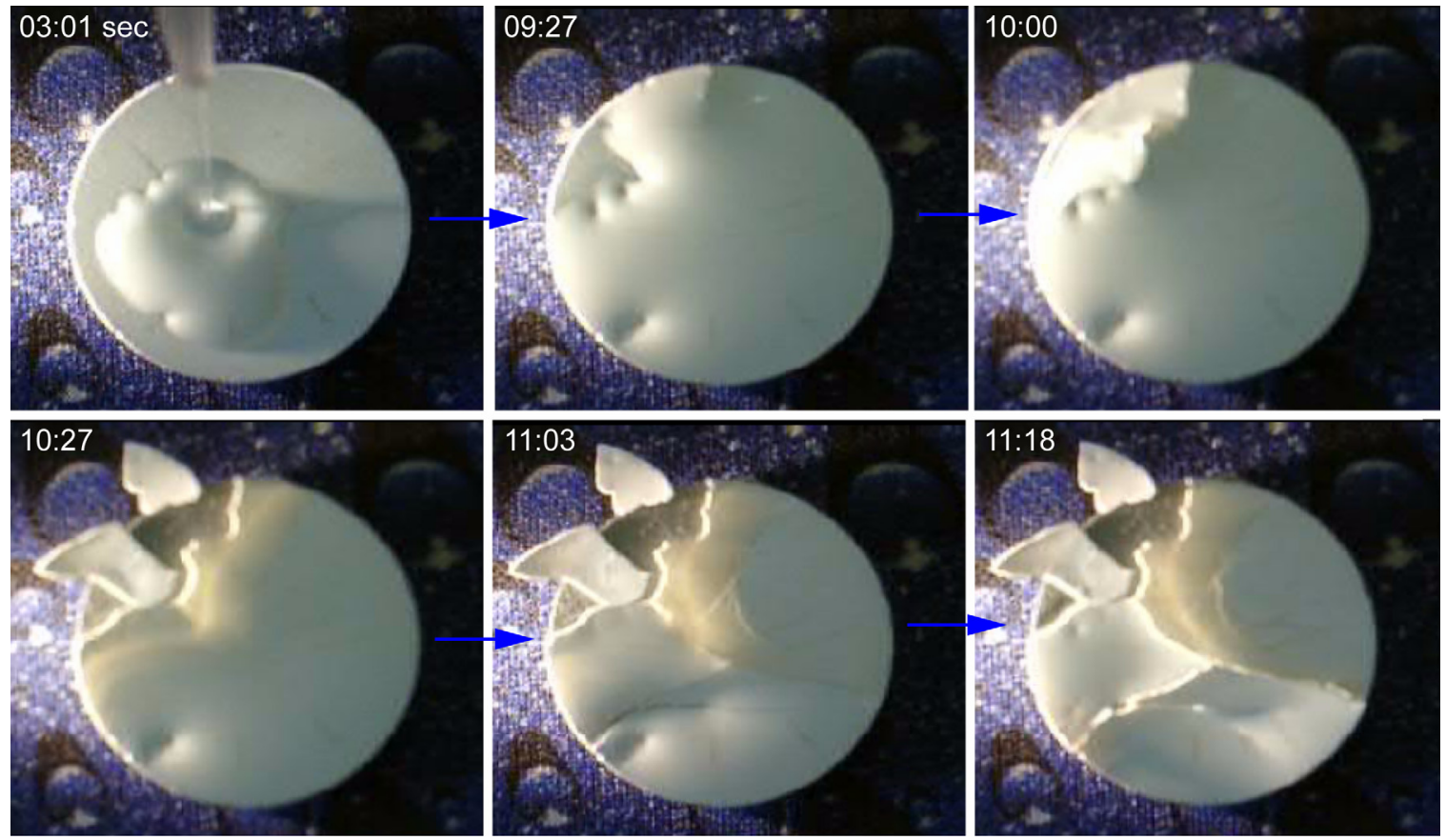

Figure 3.-Still frames from video sequence listing start times of water application and complete delamination in $9 \mathrm{sec}$. (EB-PVD TBC, pre-oxidized $300 \mathrm{hr}$ at $1150^{\circ} \mathrm{C}$ ). 


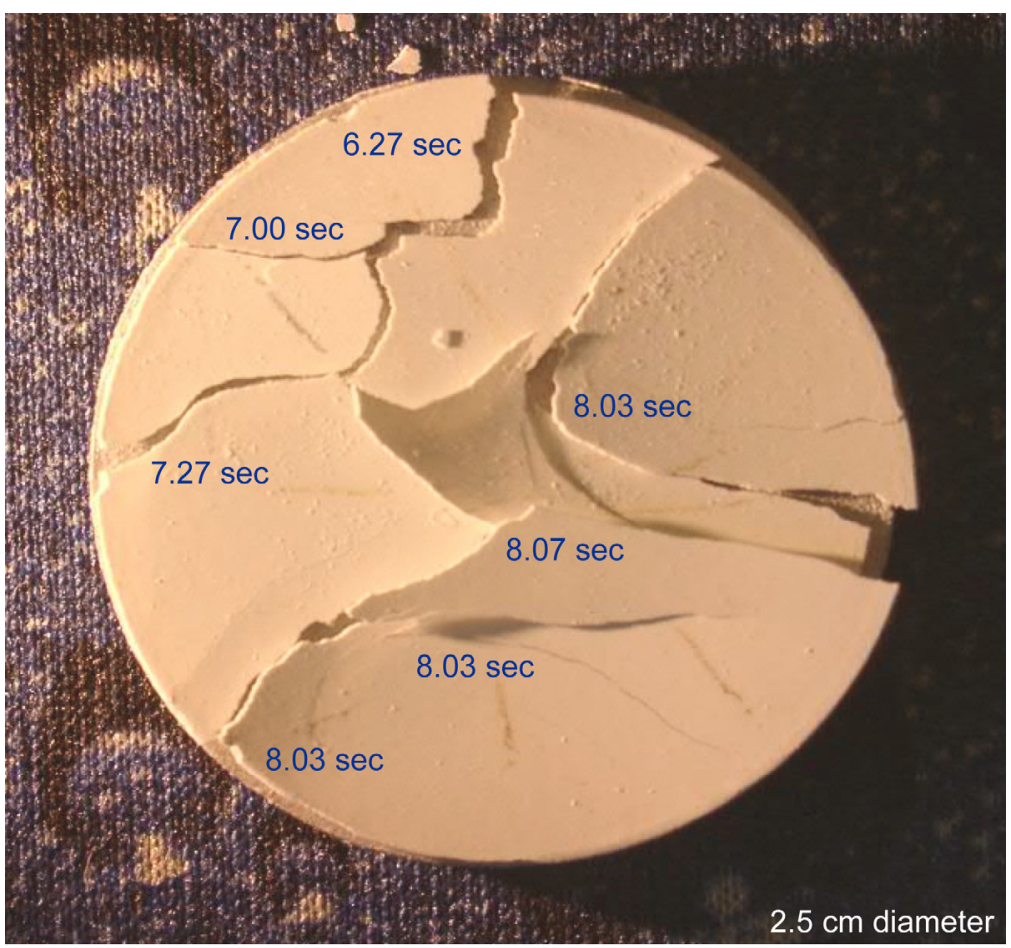

Figure 4.-Final appearance of failed TBC after water drop experiment; incubation times for specific cracks range from 6 to $8 \mathrm{sec}$.

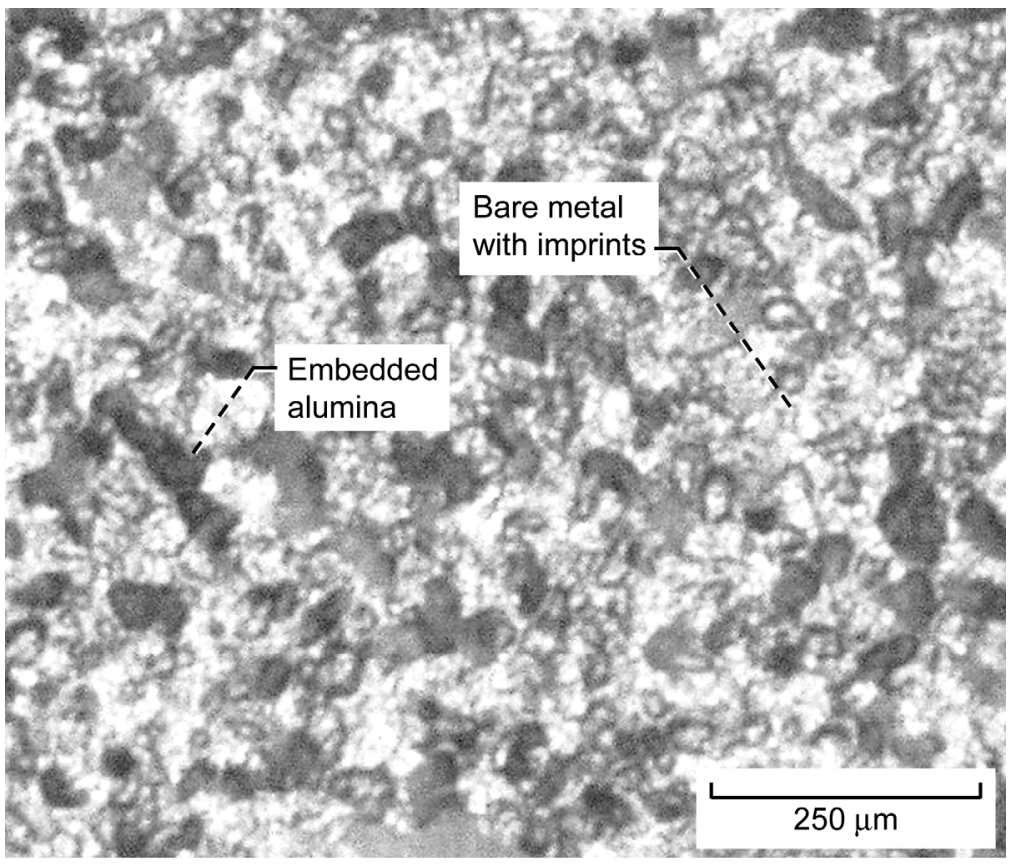

Figure 5.-Macrograph of exposed bond coat metal after TBC failure, indicating $\mathrm{Al}_{2} \mathrm{O}_{3}$ spallation to bare metal and trapped $\mathrm{Al}_{2} \mathrm{O}_{3}$ oxide intrusions. 
of four sister compositions in the same test but at about 20 to $80 \mathrm{hr}$ earlier. (The overall FCT lifetimes are summarized in table 1 and the lives, based on total oxidation time, compare reasonably well to those measured in previous tests at $1163^{\circ} \mathrm{C}$ (ref. 10)). By retaining the adhesion of the coating after complete cooldown from the oxidation temperature, the system indicates that the thermal expansion mismatch stress in the scale (biaxial compression) did not provide sufficient strain energy to cause failure immediately. However, the application of moisture in the form of a few water droplets apparently provided the final impetus.

\begin{tabular}{|c|c|c|c|c|}
\hline \multirow{3}{*}{ Coatings } & \multirow{2}{*}{\multicolumn{2}{|c|}{$\begin{array}{c}1150^{\circ} \mathrm{C}, \\
1 \mathrm{hr} \text { cycles }\end{array}$}} & \multirow{2}{*}{\multicolumn{2}{|c|}{$\begin{array}{c}1163{ }^{\circ} \mathrm{C} \\
0.75 \mathrm{hr} \text { cycles }\end{array}$}} \\
\hline & & & & \\
\hline & hours & cycles & hours & cycles \\
\hline (1) 4 YSZ baseline & 260 & 260 & 225 & 300 \\
\hline (6) RE doped YSZ, average & 297 & 297 & 240 & 320 \\
\hline (1) $2 \mathrm{YO}_{1.5}-1.5 \mathrm{GdO}_{1.5}-1.5 \mathrm{YbO}_{1.5}$ & 300 & 300 & 280 & 373 \\
\hline
\end{tabular}

\section{Discussion}

The direct connection and implication is that moisture deteriorates the scale-metal interfacial strength. This is consistent with many other observations of alumina scale spallation, but the present work provides the first video of water-induced TBC failure. The atomistics have been discussed in terms of moisture-induced increased crack growth rates in bulk alumina as well as reduced interfacial strength and toughness. It can be surmised that these both involve hydroxylation of aluminum atoms to form $\mathrm{Al}(\mathrm{OH})_{3}$, either from the alumina scale or from aluminum metal from an exposed interface, respectively. More specifically, it was proposed (ref. 12) that hydrogen embrittlement was enabled from the following interfacial reaction, following the model presented for bulk aluminides:

$$
\mathrm{Al}_{\text {alloy }}+3 \mathrm{H}_{2} \mathrm{O}=\mathrm{Al}(\mathrm{OH})_{3}+3 \mathrm{H}^{+}+3 \mathrm{e}^{-}
$$

A host of circumstantial similarities to well-established hydrogen embrittlement phenomena in metals reinforces this hypothesis (ref. 12):

(1) An interfacial nature of embrittlement

(2) First principles prediction of $\mathrm{H}$-reductions in $\mathrm{M}-\mathrm{M}$ and $\mathrm{Ni}-\mathrm{Al}_{2} \mathrm{O}_{3}$ strength

(3) A negative synergistic effect with another interfacial segregant (sulfur)

(4) A preference for a multi-axial tensile stress state

(5) A maximum effect near room temperature, with a time delay

(where hydrogen diffusion in $\mathrm{Ni}$ is rapid enough to enter the metal, but slow enough to allow build up without escaping)

(6) Alloy and scale interfacial failure produced by cathodic hydrogen charging

(7) Moisture-induced embrittlement of $\mathrm{Ni}_{3} \mathrm{Al}$, FeAl aluminides and $\mathrm{M}-\mathrm{Al}_{2} \mathrm{O}_{3}$ scales

Based on these strong similarities and the effectiveness of a cathodic descaling (i.e., hydrogen charging) experiment, it was therefore proposed that hydrogen embrittlement plays a key role in moisture-induced delayed failure (MIDS) of alumina scales (ref. 12). Furthermore, 
since the failure appears to originate at the scale-metal interface, as seen here, desktop TBC failure most likely results from moisture-induced hydrogen embrittlement as well.

The preconditions supporting this phenomenon are: a high tensile stress state in the bond coat at the interface, interfacial exposure to moisture for a period of time to allow hydrogen diffusion, and prior segregation of sulfur. Correspondingly, CTE mismatch produces a high biaxial stress state in the metal (refs. 1 and 13), microcracks observed in the TBC provide moisture access to the scale-metal interface, some finite amount of time is required for delayed spallation, hydrogen is detected beneath failed coatings (ref. 14), and Pt-aluminide coatings do eventually exhibit some sulfur segregation, though reduced from segregation levels for Pt-free aluminides (refs. 15 and 16).

While the present experiment with liquid water produced an immediate dramatic TBC failure, conventional cycling under ambient conditions (60 to 70 percent relative humidity) show analogous, delayed desktop failure. However, the ultimate connection between these observations and actual turbine performance is more problematic. Combustion of jet fuel produces about 10 percent water vapor at high pressures, which might suggest a propensity for moisture-induced failure. However, combustion takes place at high temperature, where hydrogen leaves as fast as it diffuses into a metal. After cooldown the only exposure to moisture then would be the ambient humidity. Furthermore, maximum bond coat design temperatures for internally cooled airfoils $\left(1050^{\circ} \mathrm{C}\right)$ are lower than the accelerated $1150{ }^{\circ} \mathrm{C}$ test here. Qualitatively, this implies thinner scales, less strain energy, less bond coat creep and ratcheting effects, and less CTE mismatch stress. These factors encourage intact scales. Thus moisture access and moisture-induced interfacial failure would be reduced proportionally and possibly delayed indefinitely in actual service. While this apparent discrepancy between lab tests and engine experience is acknowledged, the potential for moisture-induced damage has been unequivocally demonstrated here for this EB-PVD system and for an APS system in reference 9.

\section{Summary}

Commercially produced RE-modified TBCs were obtained on Rene'N5 Ni-base single crystal samples with a Pt-aluminide bond coat. Furnace testing in air at $1150{ }^{\circ} \mathrm{C}$ using 1 -hr cycles produced TBC failure generally between 200 to $300 \mathrm{hr}$. A coating that remained intact at $300 \mathrm{hr}$ was then shown to fail just by the application of a few drops of water. A video sequence documented an incubation time of $6 \mathrm{sec}$, with total delamination occurring in $3 \mathrm{sec}$. The failure locus was primarily at the scale-metal interface. This phenomenon is believed to be analogous to desktop spallation (DTS) of TBCs and another manifestation of moisture-induced delayed spallation (MIDS) of alumina scales. A chemical mechanism is proposed to originate from hydroxylation of aluminum in the metal, enabling hydrogen embrittlement of the interface. It is most apparent when TBC failure is already imminent, needing cracks for moisture access to a highly stressed and weakened scale-metal interface.

\section{References}

1. R.A. Miller, J. Amer. Ceram. Soc., 67, 517-521 (1984).

2. A.G. Evans, D.R. Mumm, J.W. Hutchinson, G.H. Meier, and F.S. Pettit, Progress in Materials Science, 46, 505-553 (2001). 
3. J.L. Smialek and G.N. Morscher, Materials Science and Engineering: A, 332 (1-2), 11-24, (2002).

4. R. Janakiraman, G.H. Meier, and F.S. Pettit, Metall. and Mat. Trans., 30A, 2905-2913 (1999).

5. V. Sergo and D.R. Clarke, J. Amer. Ceram. Soc., 81 [12] 142-161 (1998).

6. V. Tolpygo and D.R. Clarke, Mater. Sci. Eng., A278, 142-161 (2000).

7. J.L. Smialek, Ceramic Engineering and Science Proceedings, 23, 4, 485-495 (2002).

8. D. Renusch, H. Eschler, and M. Schütze, Mat. High Temp., 21, 65-76 (2004).

9. M. Rudolphi, D. Renusch, and M. Schütze, Scripta mat., in press.

10. D. Zhu and R.A. Miller, "Low conductivity and sintering-resistant thermal barrier coatings," US Patent No. 6,812,176, November 2, 2004.

11. J.L. Smialek and B.A. Pint, Mater. Sci. Forum, 369-372, 459-66 (2001).

12. J.L. Smialek, JOM, 1, 29-36 (Jan. 2006).

13. V.K. Tolpygo and D.R. Clarke, Oxid. Met., 49, 187-212 (1998).

14. H.E. Zschau, M. Dietrich, D. Renusch, M. Schütze, J. Meijer, and H.W. Becker, Nuclear Instruments and Methods B, 249, 381-383 (2005).

15. P.Y. Hou and K.F. McCarty, Scripta mat., 54, 937-941 (2006).

16. Y. Cadoret, M.-P. Bacos, P. Jasso, V. Maurice, P. Marcus, and S. Zanna, Materials Science Forum, 461-464, 247-254 (2004). 


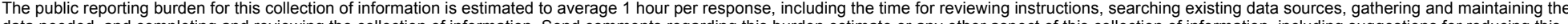

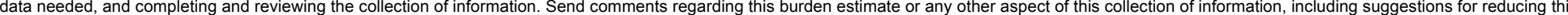

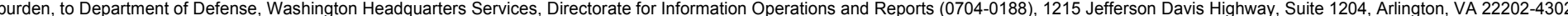

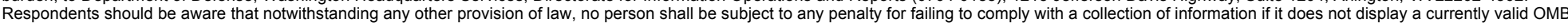
control number.

PLEASE DO NOT RETURN YOUR FORM TO THE ABOVE ADDRESS.
1. REPORT DATE (DD-MM-YYYY)
2. REPORT TYPE
3. DATES COVERED (From - To)

01-04-2008

Technical Memorandum

\section{TITLE AND SUBTITLE}

Moisture-Induced Delamination Video of an Oxidized Thermal Barrier Coating

\section{5a. CONTRACT NUMBER}

5b. GRANT NUMBER

5c. PROGRAM ELEMENT NUMBER

\section{AUTHOR(S)}

Smialek, James, L.; Zhu, Dongming; Cuy, Michael, D.

\section{5d. PROJECT NUMBER}

5e. TASK NUMBER

5f. WORK UNIT NUMBER

WBS 984754.02.07.03.16.02

\section{PERFORMING ORGANIZATION NAME(S) AND ADDRESS(ES)}

National Aeronautics and Space Administration

\section{PERFORMING ORGANIZATION REPORT NUMBER}

John H. Glenn Research Center at Lewis Field

E-16484

Cleveland, Ohio 44135-3191

\section{SPONSORING/MONITORING AGENCY NAME(S) AND ADDRESS(ES)}

National Aeronautics and Space Administration

Washington, DC 20546-0001

\section{SPONSORING/MONITORS ACRONYM(S) \\ NASA}

11. SPONSORING/MONITORING REPORT NUMBER

NASA/TM-2008-215210

\section{DISTRIBUTION/AVAILABILITY STATEMENT}

Unclassified-Unlimited

Subject Categories: 26 and 27

Available electronically at http://gltrs.grc.nasa.gov

This publication is available from the NASA Center for AeroSpace Information, 301-621-0390

\section{SUPPLEMENTARY NOTES}

\section{ABSTRACT}

PVD TBC coatings were thermally cycled to near-failure at $1150{ }^{\circ} \mathrm{C}$. Normal failure occurred after 200 to 3001 -hr cycles with only moderate weight gains $\left(0.5 \mathrm{mg} / \mathrm{cm}^{2}\right)$. Delamination and buckling was often delayed until well after cooldown (desktop spallation), but could be instantly induced by the application of water drops, as shown in a video clip which can be viewed by clicking on figure 2 of this report. Moisture therefore plays a primary role in delayed desktop TBC failure. Hydrogen embrittlement is proposed as the underlying mechanism. 15. SUBJECT TERMS

Oxidation; Thermal control coatings; Heat resistant alloys; Moisture; Hydrogen embrittlement

\begin{tabular}{|c|c|c|c|}
\hline \multicolumn{3}{|c|}{ 16. SECURITY CLASSIFICATION OF: } & \multirow{2}{*}{$\begin{array}{l}\text { 17. LIMITATION OF } \\
\text { ABSTRACT } \\
\text { UU }\end{array}$} \\
\hline $\begin{array}{l}\text { a. REPORT } \\
\mathrm{U}\end{array}$ & $\begin{array}{l}\text { b. ABSTRACT } \\
U\end{array}$ & $\begin{array}{l}\text { c. THIS } \\
\text { PAGE } \\
\text { U }\end{array}$ & \\
\hline
\end{tabular}

18. NUMBER
OF
PAGES
14
19a. NAME OF RESPONSIBLE PERSON STI Help Desk (email:help@sti.nasa.gov) 19b. TELEPHONE NUMBER (include area code) 301-621-0390



